\title{
Structure elucidation of 11-epiterpestacin glycoside (11-ETG) isolated from Bipolaris sorokiniana NSDR-011
}

\author{
Chi-Hwan Lim $^{1}$ (D) $\cdot$ Youichirou Nihashi ${ }^{2}$
}

Received: 8 February 2018 / Accepted: 26 February 2018 / Published Online: 31 March 2018

(C) The Korean Society for Applied Biological Chemistry 2018

\begin{abstract}
An $\alpha$-D-glucoside of sesterterpene, 11-epiterpestacin, was isolated from the culture of a filamentous fungus Bipolaris sorokiniana NSDR-011. The structure was elucidated by chemical studies and spectroscopic methods including NMR and ESI-MS. 11-ETG (1) named arbitrarily did not inhibit the root growth of Italian ryegrass seedlings even at the level of $200 \mathrm{ppm}$, while its aglycone 11-ET (2) completely inhibited root growth at level of $100 \mathrm{ppm}$.
\end{abstract}

Keywords Bipolaris sorokiniana $\cdot 11$-epiterpestacin (11-ET) · 11-epiterpestacin glucoside $(11$-ETG) $\cdot$ Phytotoxin · Sesterterpene

\section{Introduction}

Plant pathogenic fungi are well known to produce various types of phytotoxic compounds that are difficult to artificially synthesize. Such compounds often represent the lead for new plant growth regulator (Scheffer et al. 1983). In the course of our search for new phytotoxic substances from plant pathogenic fungi, we previously reported that a pair of bicyclo 5-15-fused sesterterpene isomers, referred to as terpestacin (Oka et al. 1993) and 11epiterpestacin (11-ET, 2), were isolated from the cultures of two distinct fungal strains, B. sorokiniana and B. cynodontis,

Chi-Hwan Lim $(\square)$

E-mail: chlim@cnu.ac.kr

${ }^{1}$ Department of Bio-Environmental Chemistry, College of Agricultural Biology \& Life Science, Chungnam National University, Taejeon 305-600, Republic of Korea

${ }^{2}$ Shionogi \&Co, LTD, 3-1-1, Futaba-Cho, Toyonaka, Osaka 561-0825, Japan

This is an Open Access article distributed under the terms of the Creative Commons Attribution Non-Commercial License (http://creativecommons. org/licenses/by-nc/3.0/) which permits unrestricted non-commercial use, distribution, and reproduction in any medium, provided the original work is properly cited. respectively ( $\operatorname{Lim}$ et al. 1995; Lim et al. 1996; Nihashi et al. 2002). From the culture of $B$. sorokiniana, an acetylated derivative of 11-ET, fusaproliferin (3) was also isolated (Santini et al. 1996). In this paper, we report the isolation and structural analysis of another terpestacin-related compound, 11-ETG (1), which was found in the culture of B. sorokiniana.

\section{Materials and Methods}

\section{Fungus and plant}

The fungal strain, $B$. sorokiniana NSDR-011 had originally been isolated from a decayed ryegrass leaf with brown spot lesions. Its identification was based on the DNA sequence of Brnl (Shimizu et al. 1997). Italian ryegrass (Lolium multiforum Lam.) was used for the assay, the seed of which were purchased from Takii Seed company (Kyoto, Japan).

\section{Spectroscopic measurements}

Optical rotations were measured on a Jasco model J-5. The IR spectra were determined on a Pye Unicam SP 3200 Infra-Red Spectrophotometer. Electron ionization mass spectra (EI-MS) were obtained on a Hitachi M-80A. The ${ }^{1} \mathrm{H}$ and ${ }^{13} \mathrm{C}$ NMR spectra were determined on a Bruker AC $300\left(300 \mathrm{MHz}\right.$ for ${ }^{1} \mathrm{H}$ and 75 $\mathrm{MHz}$ for ${ }^{13} \mathrm{C}$ ) and/or Bruker ARX $500\left(500 \mathrm{MHz}\right.$ for ${ }^{1} \mathrm{H}$ and 125 $\mathrm{MHz}$ for ${ }^{13} \mathrm{C}$ ). High performance liquid chromatography (HPLC) was performed on Hitachi L-6200 apparatus equipped with an L$4200 \mathrm{H}$ UV-Vis detector using a Cosmosil octadecyl silica (ODS) column. Gas chromatography (GC) was performed by a Hitachi G-5000 equipped with an FID detector using a "Quadrex" bonded methyl silicone fused silica capillary column $0.25 \mathrm{~mm} \times 25 \mathrm{~m}$.

Isolation and purification of 11-ETG. The fungus was cultured on a PSA medium in Petri dishes (90 mm i.d.) for 14 days in the dark at $25^{\circ} \mathrm{C}$. The agar plates with mycelial body were soaked in acetone, and the acetone extract was filtered and concentrated under reduced pressure at $40{ }^{\circ} \mathrm{C}$. The resulting aqueous solution was re-extracted with ethyl acetate, and the solvent was removed 
under reduced pressure to obtain a crude extract. This material was subjected to silica gel column chromatography, using a gradient solvent system from $n$-hexane to ethyl acetate, and then to methanol. 11-ETG was detected as a major component in the methanol fraction by HPLC. The compound was further purified by HPLC with a Cosmosil ODS column, UV detector (254 nm), and a mobile phase of $\mathrm{MeOH} / \mathrm{H}_{2} \mathrm{O}(80 / 20)$. 11-ETG was obtained as amorphous solid material with a yield of $47 \mathrm{mg}$ from 1,000 agar plates.

\section{Physicochemical data of 11-ETG}

$[\alpha] \mathrm{D}+26.7^{\circ}\left(\mathrm{c} 0.83, \mathrm{CHCl}_{3}\right),{ }^{13} \mathrm{C}$ NMR $\left(125 \mathrm{MHz}\right.$, methanol-d $\left.\mathrm{d}_{4}\right)$ $\delta: 208.9$ (C18), 150.2 (C17), 147.8, 137.9, 132.4, 129.0, 124.0, 122.1, 100.0 (C1'), 75.7 (C11), 73.8 (C3'), 72.5 (C5'), 72.2 (C2'), 70.4 (C4'), 70.0 (C24), 61.3 (C6'), 48.9 (C15), 48.7 (C1), 40.1, $38.9,34.8,34.5,29.5,28.8,23.5,15.7,14.3,14.1,13.9,9.0,{ }^{1} \mathrm{H}$ NMR (500 MHz, methanol-d $\left.\mathrm{d}_{4}\right) \delta: 5.42(1 \mathrm{H}, \mathrm{m}, \mathrm{H}-13), 5.33(1 \mathrm{H}$, m, H-3), 5.17 (1H, m, H-7), 4.78 (1H, d, $J=3.7$ Hz, H-1'), 4.00$3.55(7 \mathrm{H}), 3.40-3.25(2 \mathrm{H}), 2.90-2.80(2 \mathrm{H}), 2.55-2.00(7 \mathrm{H}), 2.00-$ $1.60(5 \mathrm{H}), 1.64(6 \mathrm{H}, \mathrm{s}), 1.56(3 \mathrm{H}, \mathrm{s}), 1.33(3 \mathrm{H}, \mathrm{d}, J=7.0 \mathrm{~Hz}, \mathrm{C} 25-$ methyl), 0.93 (3H, s), EI-MS m/z: $564\left(\mathrm{M}^{+}\right), 402,384,137,81$ (base peak), 55.

\section{Acetylation of 11-ETG}

11-ETG $(17.6 \mathrm{mg})$ was treated with acetic anhydride $(1.5 \mathrm{~mL})$ and pyridine $(1.5 \mathrm{~mL})$ at $40{ }^{\circ} \mathrm{C}$ for 24 hours. The mixture was poured into a small amount of ice-water to decompose the unreacted acetic anhydride. The solvents were eliminated by vacuum evaporation followed by a stream of $\mathrm{N}_{2}$ for $5 \mathrm{~h}$. The product was purified by chromatography on a Cosmosil ODS column $(20$ i.d. $\times 250 \mathrm{~L} \mathrm{~mm}$ ) eluted with $80 \%$ aq. $\mathrm{MeOH}$ to obtain a pure acetyl derivative as pale-yellow oil (14.6 mg).

${ }^{13} \mathrm{C}$ NMR (75 MHz, $\mathrm{CDCl}_{3}$ ) $\delta: 206.9$ (C18), 170-165 (acetyl carbonyl×6), 144.9 (C16), 138.2 (C4), 132.8 (C12), 132.3 (C8), 130.8 (C13), 124.2 (C7), 121.1 (C3), 95.8 (C1'), 78.7 (C11), 70.7 (C24), 70.5 (C2'), 69.9 (C3'), 68.7 (C4'), 67.5 (C5'), 62.0 (C6'), 49.9 (C15), 49.8 (C1), 40.0 (C5), 39.0 (C2), 34.6 (C23), 34.4 (C9), 28.6 (C12), 27.7 (C14), 23.9 (C6), 23-20 (acetyl methyl $\times 6$ ), 16.0 (C19), 15.7 (C20), 15.4 (C21), 15.1 (C25), 11.1 (C22), ${ }^{1} \mathrm{H}$ NMR $\left(300 \mathrm{MHz}, \mathrm{CDCl}_{3}\right) \delta: 5.53(1 \mathrm{H}$, br d, $J=5.9 \mathrm{~Hz}, \mathrm{H}-13)$, 5.43 (1H, dd, $J=9.5,10.1 \mathrm{~Hz}, \mathrm{H}-3$ '), 5.2 (1H, m, H-11), 5.20-5.05 $(2 \mathrm{H}, \mathrm{H}-5, \mathrm{H}-7), 5.05(1 \mathrm{H}, \mathrm{dd}, J=9.8,9.8 \mathrm{~Hz}, \mathrm{H}-4), 5.00(1 \mathrm{H}, \mathrm{d}$, $\left.J=3.7 \mathrm{~Hz}, \mathrm{H}-1^{\prime}\right), 4.86$ (1H, dd, $J=3.7,10.3 \mathrm{~Hz}, \mathrm{H}-2$ '), 4.26 (1H, $\left.\mathrm{dd}, J=4.5,12.3 \mathrm{~Hz}, \mathrm{H}-6 \mathrm{a}^{\prime}\right), 4.10$ (1H, dd, $\left.J=2.4,12.3 \mathrm{~Hz}, \mathrm{H}-6 \mathrm{~b}^{\prime}\right)$, 4.00 (1H, ddd, $J=2.4,4.4,10.2 \mathrm{~Hz}, \mathrm{H}-5$ '), 3.75 (1H, dd, $J=7.0$, $9.3 \mathrm{~Hz}, \mathrm{H}-24 \mathrm{a}), 3.49$ (1H, dd, $J=7.4,9.5 \mathrm{~Hz}, \mathrm{H}-24 \mathrm{~b}), 2.90-2.80$ $(2 \mathrm{H}, \mathrm{H}-15, \mathrm{H}-23), 2.50-1.60(12 \mathrm{H}), 2.24-1.98$ (18H, s, acetyl methyl $\times 6), 1.65(3 \mathrm{H}, \mathrm{s}, \mathrm{C} 20$-methyl)

\section{Analysis of the hexose moiety of 11-ETG}

11-ETG $(3.0 \mathrm{mg})$ was dissolved in $3 \mathrm{~N} \mathrm{HCl}(5 \mathrm{~mL})$. The reaction mixture was maintained with stirring at $75^{\circ} \mathrm{C}$ for $4 \mathrm{~h}$. After the

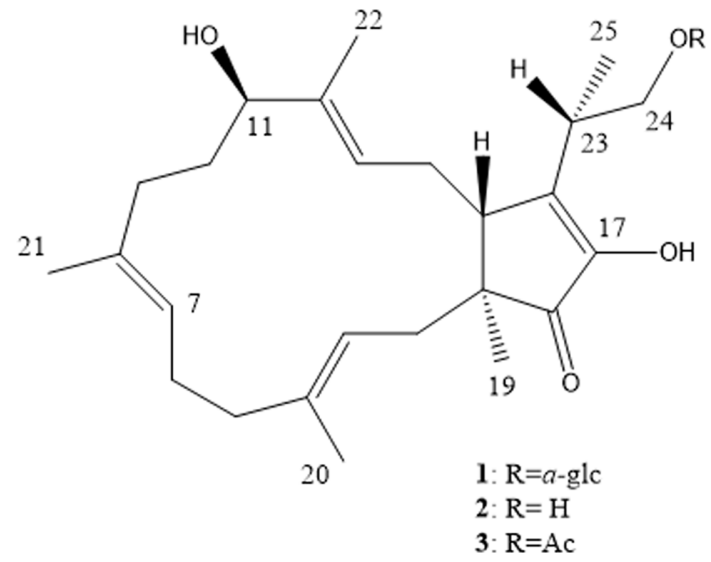

Fig. 1 Structure of 11-ETG (1), 11-epiterpestacin (2), and fusaproliferin (3)

completion of the reaction, the solvent was evaporated in vacuo. The residue was subjected to C18 Sep-Pak cartridge (Waters), eluting with a $\mathrm{H}_{2} \mathrm{O}$ to obtain the hexose fraction. Trimethylsilylating (TMS) Reagent (Tokyo Kasei Kogyo Co., $500 \mu \mathrm{L}$ ) was added to the dried hexose fraction, and the reaction mixture was vigorously stirred for a while, then directly subjected to GC analysis. By using the same procedure, TMS derivatives of D-(+)glucose, D-(-)-fructose, and D-(+)-galactose were prepared for comparison.

In another experiment, 11-ETG (37 mg) was dissolved in $10 \%$ $\mathrm{HCl}-\mathrm{MeOH}(5 \mathrm{~mL})$ and heated under reflux for $6 \mathrm{~h}$. The reaction mixture was neutralized with $\mathrm{Ag}_{2} \mathrm{CO}_{3}$ and the resultant precipitate was filtered off. The methyl glucoside yielded $(13 \mathrm{mg})$ was purified by using a $\mathrm{C} 18$ Sep-Pak cartridge, and then acetylated with acetic anhydride and pyridine. After removing the solvent, the syrup obtained $(28 \mathrm{mg})$ was purified by silica gel TLC ( $n$-hexane : ether : tetrahydrofuran $=33: 66: 1)$ to afford methyl $\alpha$-D-glucopyranoside tetraacetate $(6 \mathrm{mg})$ and its $\beta$-isomer $(8 \mathrm{mg})$.

\section{Phytotoxicity assay}

A specified amount of the test compound in $\mathrm{MeOH}$ was applied to a Petri dish (35 $\mathrm{mm}$ in diameter) in which two layers of Whatman No. 2 filter paper were laid. After the solvent was evaporated, one $\mathrm{mL}$ of water containing $0.5 \%$ Tween 20 (Nakarai Chemicals Ltd., Kyoto, Japan) was added to the dish to dissolve the test compound. Uniformly germinated seeds were selected, with roots ca. $2 \mathrm{~mm}$ in length, and placed in the dish (nine seeds per plate) and incubated in a dark condition at $26^{\circ} \mathrm{C}$ for $72 \mathrm{~h}$. The inhibitory activity was evaluated by comparing the root length to that of the control.

\section{Results and Discussion}

Structure elucidation of 11-ETG

The ${ }^{1} \mathrm{H}-\mathrm{NMR}$ and ${ }^{13} \mathrm{C}-\mathrm{NMR}$ spectra of 11 -ETG were very similar 


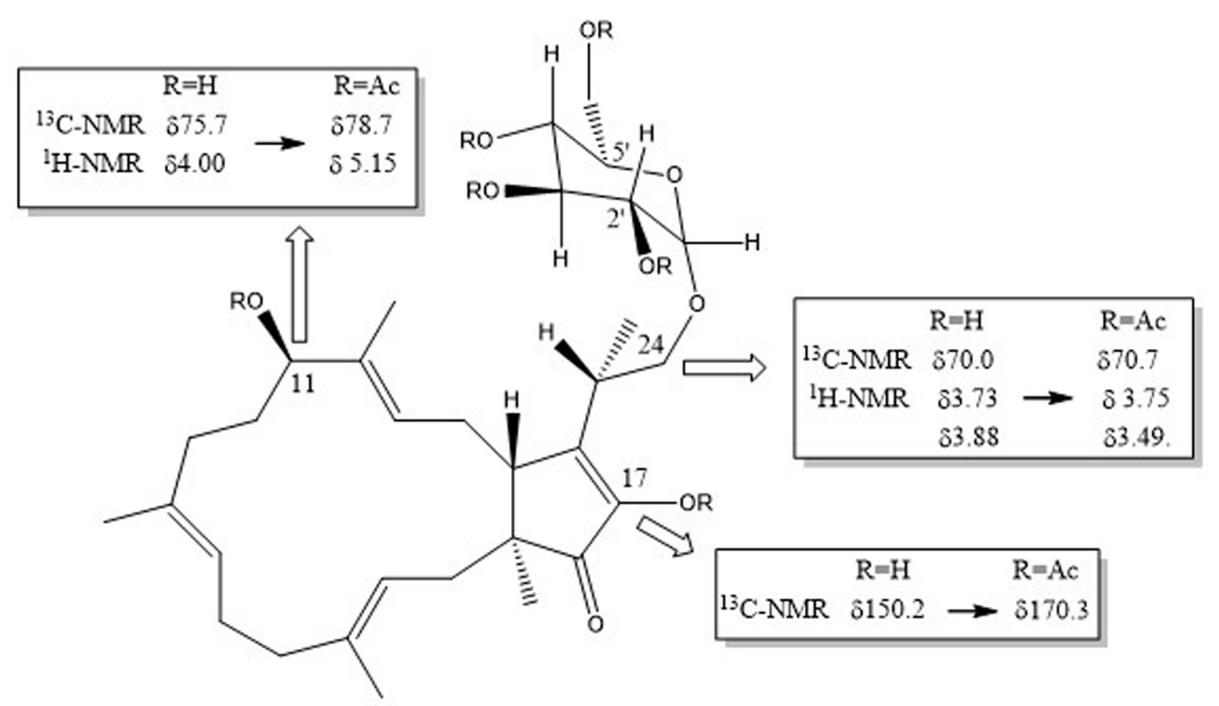

Fig. 2 NMR chemical shift change of 11-ETG (1) according to acetylation reaction

to those of the 11-ET except the signals assignable to the hexose

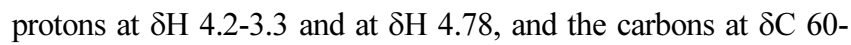
75 and $\delta \mathrm{C} 100$. The signal at $\delta \mathrm{C} 100 \mathrm{ppm}$ was characteristic of an anomeric carbon of the sugar moiety. The EI-mass spectra of 11ETG showed a molecular ion at $m / z 564$, which is larger than 11ET (M.W. 402) by 162 m.u. of a dehydrated hexose $\left(\mathrm{C}_{6} \mathrm{H}_{12} \mathrm{O}_{6^{-}}\right.$ $\mathrm{H}_{2} \mathrm{O}$ ). These data suggested that 11-ETG was a monoglycoside of 11-ET.

Acetylation of 11-ETG afforded a hexaacetyl derivative, which was evidenced by its EI-mass spectrum and ${ }^{1} \mathrm{H}-\mathrm{NMR}$ spectrum. EI-mass spectrum showed $[\mathrm{M}]^{+}$at $m / z 816\left(564+\left(\mathrm{CH}_{3} \mathrm{CO} \times 6\right)-\right.$ $6 \mathrm{H})$ and the ${ }^{1} \mathrm{H}-\mathrm{NMR}$ spectrum showed the presence of six acetyl methyl groups. The presence of hexose moiety was again supported by a series of typical fragment peaks from an acetylated hexose $(m / z 331,169,109,43)$ in the MS. The six alcoholic hydroxy groups in 11-ETG were reasonably assigned to two hydroxyl groups in the 11-ET moiety and four hydroxyl groups in hexose moiety. Furthermore, the methine proton at $\delta \mathrm{H} 5.00$ was correlated to the anomeric carbon at $95.8 \mathrm{ppm}$ in the ${ }^{1} \mathrm{H}-{ }^{13} \mathrm{C}$ COSY spectrum, and the ${ }^{1} \mathrm{H}-{ }^{1} \mathrm{H}$ COSY data showed the correlation from the signal $\delta \mathrm{H} 5.43$ to the six proton signals in the range of $\delta \mathrm{H} 4.0-5.0 \mathrm{ppm}$ in order. By acetylation, the chemical shifts of the signals that corresponded to those of $\mathrm{H}-11(\delta \mathrm{H} 4.00)$ and $\mathrm{C}-17$ ( $\delta \mathrm{C} 150.2)$ in 11-ETG were moved down field $(\delta \mathrm{H} 5.15$ and $\delta \mathrm{C} 170.3$ ) respectively (Fig. 2). The presence of glucose moiety in 11-ETG was also supported by the analysis of the proton coupling constants in the NMR spectrum of 11-ETG. The large vicinal coupling constants observed between $\mathrm{H}-2^{\prime}$ and $\mathrm{H}-3^{\prime}$ (10.3 Hz), H-3' and H-4' (9.8 Hz), and H-4' and H-5' (10.0 Hz) indicated that these four protons were arranged with each other in a trans diaxial configuration, which is consistent with that found in glucopyranose. The configuration of the glucoside bond was determined to be alpha by the small coupling constants between

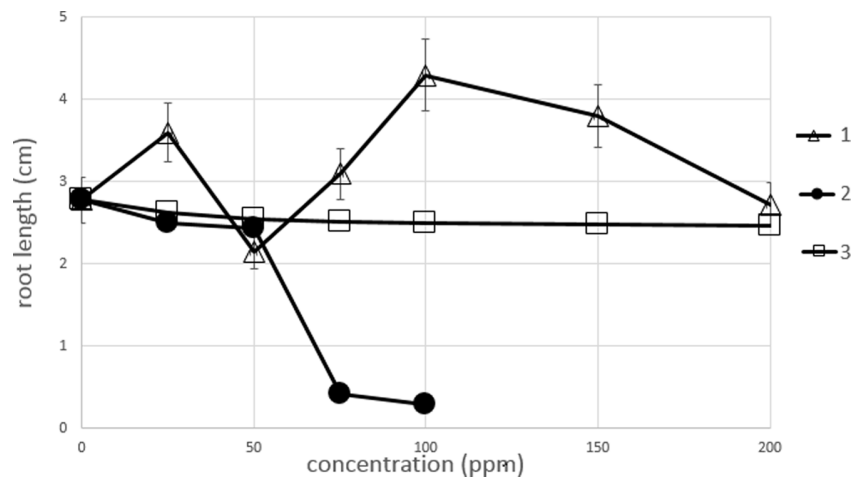

Fig. 3 Italian ryegrass seedlings root growth inhibitory activity by 11ETG (1), 11-epiterpestacin (2), and fusaproliferin (3)

anomeric proton $\mathrm{H}-1^{\prime}$ and $\mathrm{H}-2^{\prime}(J=3.7 \mathrm{~Hz})$.

Based on these findings, 11-ETG was concluded to be $\alpha$ glucopyranoside of 11-ET at the 24-hydroxyl group.

\section{Phytotoxicity assay}

11-ETG (1) did not inhibit the root growth of Italian ryegrass seedlings even at the level of $200 \mathrm{ppm}$, while its aglycone 11-ET (2) completely inhibited root growth at the level of $100 \mathrm{ppm}$ (Fig. 3). The lower hydrophobicity of 11-ETG relative to 11-ET, due to the presence of glucose moiety, is likely to be responsible for the lower phytotoxicity. This is in contrast with the case of fusicoccins, phytotoxins produced by a plant pathogenic fungus Phomopsis (Fusicoccum) amygdali. Fusicoccins are structurally related to 11-ETG in that they are terpenoid (diterpene) glucosides, and it has been shown that the glucose moiety, although it is modified with an additional isoprene moiety, in the toxins is important for the expression of toxicity (Ballio et al. 1964, Toyomasu et al. 2007). 
The phytotoxicity of 11-ET suggests that this compound plays an important role in the expression of disease symptoms by this fungus, but it is also possible that the toxin also has more or less negative effect on the growth of the producer fungus itself. If so, the production of 11-ETG in the fungus can serve for detoxification. It is unlikely that plants have comparable detoxification mechanism against such a toxin with specific chemical structure. A comparative analysis of the glycosidation activity of terpenoids between fungi and plants may raise an issue of plant pathological interest.

Acknowledgments This work was supported by a grant from Chungnam National University.

\section{References}

Ballio A, Chain EB, De Leo P, Erlanger BF, Mauri M, Tonolo A (1964) Fusicoccin: a new wilting toxin produced by Fusicoccum amygdali. Nature 203 (4942): 297

Lim CH, Miyagawa H, Ueno T, Takenaka H, Sung ND (1996) Siccanol: sesterterpene isolated from pathogenic fungus Drechslera siccans. Agric
Chem Biotechnol 39: 241-244

Lim CH, Miyagawa H, Ueno T, Takenaka H, Tsurushima T (1995) Isolation and structure elucidation of terpenoid phytotoxins produced by the plant pathogenic fungus Bipolaris cynodontis. In abstracts of Papers of $37^{\text {th }}$ Symposium on the Chemistry of Natural Products, Tokushima, Japan, 325-330

Nihashi Y, Lim CH, Tanaka C, Miyagawa H, Tamio U (2002) Phytotoxic Sesterterpene, 11-Epiterpestacin, from Bipolaris sorokiniana NSDR-011. Biosci Biotechnol Biochem 66(3): 685-688

Oka M, Iimura S, Tenmyo O, Yamamoto H, Kawano K, Hu SL, Fukagawa Y, Oka T (1993) Terpestacin, a new syncytium formation inhibitor from Arthrinium sp.. J Antibiot 46: 367-373

Santini A, Ritieni A, Fogriano V, Randazzo G, Manniana L, Benedetti E (1996) Structure and absolute stereochemistry of fusaproliferin, a toxic metabolite from Fusarium proliferatum. J Nat Prod 59: 109-112

Scheffer RP, Daly JM, Deverall BJ (1983) Toxins and plant pathogenesis, Academic Press, New York

Shimizu K, Tanaka C, Tsuda M (1997) Cloning of Brnl, a reductase gene involved in melanin biosynthesis in Cochliobolis heterostrophus. J Gen Appl Microbiol 43: 145-150

Toyomasu T, Tsukahara M, Kaneko A, Niida R, Mitsuhashi W, Dairi T, Kato N, Sassa T (2007) Fusicoccins are biosynthesized by an unusual chimera diterpene synthase in fungi. PNAS 104 (9): 3084-3088 